\title{
COMMENTARY
}

\section{Lactate in the critically ill patients: an outcome marker with the times}

\author{
H Bryant Nguyen* \\ See related research by Nichol et al., http://ccforum.com/content/15/5/R242
}

\begin{abstract}
Lactic acid was first discovered in human blood in 1843. Since then it has been used as a prognosticator of outcome in critical illness. Regardless of its etiology, lactate's presence and trend over time have been shown to be independently associated with mortality. Two dynamic lactate measures, the time-weighted average lactate and the absolute change in lactate over the first 24 hours in the ICU, were recently shown to be better than static lactate measurements in predicting hospital and ICU deaths.
\end{abstract}

Since the beginning of the 21st century, with evidence that effective treatment of septic shock requires early recognition supplemented by the use of lactate levels, there has been increasing interest in lactate as a diagnostic, prognostic and therapeutic guide. Lactate in its own right thus deserves a brief historical review with respect to the recent article by Nichol and colleagues [1].

Lactic acid was first discovered in sour milk in 1780 by the Swedish chemist Karl Wilhelm Scheele [2]. In January 1843, German physician-chemist Johann Joseph Scherer found lactic acid in the blood of a woman who died from postpartum septic shock [3]. This report was the beginning of numerous investigations into the utility of lactate as a marker of critical illness. Debate also arose regarding whether lactate is a measure of oxygen debt or some combination of increased production and decreased clearance. In 1964, Broder and Weil measured lactate in patients with circulatory shock. At that time, these authors stated that they 'neither support nor refute the concept that excess lactate is a valuable index of oxygen debt' [4]. However, they advocated for the prognostic value of lactate in patients with shock. Their data

*Correspondence: hbnguyen@llu.edu

Department of Emergency Medicine and Department of Medicine, Critical Care, Loma Linda University, 11234 Anderson Street, Loma Linda, CA 92354, USA supported three groups of patients with lactate elevation: lactate $\leq 1 \mathrm{mmol} / \mathrm{l}$ is a safe level; lactate of 2 to $4 \mathrm{mmol} / \mathrm{l}$ signifies a twilight zone; and lactate $>4 \mathrm{mmol} / \mathrm{l}$ reflects probable irreversible global tissue hypoxia with mortality approaching $100 \%$. Despite varying opinions over the last several decades regarding the etiology of lactate elevation in critically ill patients, the fact to date remains that it portends poor prognosis.

In 1983, Vincent and colleagues introduced the concept of serial lactate measurements as frequently as every 20 minutes during circulatory shock [5]. They observed that survivors had at least a $10 \%$ decrease in lactate during the first 60 minutes of treatment. Several investigators in the 1990s continued to study the time variable in lactate kinetics [6-8]. In patients with septic shock, the lactime - the time during which lactate levels remain $>2 \mathrm{mmol} / \mathrm{l}$ - was the best predictor of outcome in a multiple regression analysis [7]. Similarly, in trauma patients, lactate normalization within 24 hours was associated with $100 \%$ survival [6].

At the turn of the century, with the results of early goaldirected therapy, further data showed that a decrease in lactate of at least $10 \%$ during the first 6 hours of septic shock was associated with improved outcome, and a $11 \%$ decrease in mortality was observed with each $10 \%$ increase in lactate clearance [9]. Other studies have confirmed these findings and further advocated for lactate-guided treatment protocols [10-14].

In the recent article by Nichol and colleagues, both static and dynamic measurements of lactate elevation in critically ill patients were examined [1]. The authors studied 36,673 lactate measurements in 5,041 heterogeneous critically ill patients, each with at least two lactate measurements over the first 24 hours in four Australian university hospitals. Static lactate measures included admission lactate, maximum lactate, and minimum lactate; whereas dynamic lactate measures were time-weighted average lactate $\left(\mathrm{LAC}_{\mathrm{TW}_{24}}\right)$, absolute change in lactate $\left(\mathrm{LAC}_{\triangle 24}\right)$, and percentage change in lactate over the first 24 hours in the ICU. In multivariate analyses, they found that $\mathrm{LAC}_{\mathrm{TW}_{24}}$ and $\mathrm{LAC}_{\triangle 24}$ were most predictive of hospital and ICU mortality. For every unit 
increase in $\mathrm{LAC}_{\mathrm{TW}_{24}}$ or $\mathrm{LAC}_{\triangle 24}$, the risk of hospital death increased by $37 \%$ or $15 \%$, respectively. When examining prediction models that included other established risk factors such as age, gender, mechanical ventilation, and Acute Physiology and Chronic Health Evaluation II score, the addition of $\mathrm{LAC}_{\mathrm{TW}_{24}}$ and $\mathrm{LAC}_{\Delta 24}$ significantly increased the area under the receiver operating characteristics curve to 0.84 and 0.90 for predicting hospital death and ICU death, respectively. Future comparisons of the receiver operating characteristics curves of these dynamic lactate measures against known prediction models such as the Acute Physiology and Chronic Health Evaluation, the Simplified Acute Physiology Score, or the Mortality Prediction Model would also be informative.

The authors acknowledged that the study was limited by its retrospective design, lack of information on confounding patient conditions or treatments that may have affected lactate levels, and assumption that lactate kinetics was linear in nature. Additionally, the maximum (range) lactate level of 3.4 (2.0 to 6.2) $\mathrm{mmol} / \mathrm{l}$ in nonsurvivors suggested that their study population may not represent patients with a full range of abnormal lactate levels.

Nichol and colleagues' study, however, objectively confirmed what we often do at the bedside when faced with laboratory markers that have some prognostic importance. When a marker decreases after some treatment, we are relieved that we have done some good for the patient. When a marker increases significantly, we become concerned and are attentive to the patient's progress. We are more concerned if the marker worsens over an unexpected period of time. In their study, Nichol and colleagues provided a novel approach of examining the dynamic lactate changes that incorporate both the magnitude of change and the time interval of such change. Their use of the time-weighted average lactate was most intriguing and makes physiologic sense, which they modeled after the work of Finney and colleagues in glucose control [15]. $\mathrm{LAC}_{\mathrm{TW}_{24} 4}$ is determined first by multiplying the mean lactate between two consecutive time points by its time period; that is, a time-weighted lactate measurement. This computation is then repeated for each pair of consecutive lactate measurements within a 24-hour interval. The sum of all time-weighted lactate measurements is then divided by the total time period of lactate measurements to determine the time-weighted average lactate over the 24-hour period. Importantly, this approach also will provide a framework for investigators to further study trends in lactate when the clinical setting does not provide repeated lactate measurements at absolute time points. Such computation can be easily programmed in a handheld device for use at the bedside.

In summary, lactate as a marker of disease severity has survived the test of time since its first discovery in 1843 after a patient had died. Nichol and colleagues have taken it beyond a static measurement; hopefully we will continue to use and study lactate, and respect the marker's presence over time in order to prevent unnecessary patient deaths.

\section{Abbreviations}

$\mathrm{LAC}_{\Delta 24^{\prime}}$ absolute change in lactate over the first 24 hours; $L A C_{T W 24^{\prime}}$ timeweighted average lactate over the first 24 hours.

\section{Competing interests}

The author declares that he has no competing interests.

Published: 5 December 2011

\section{References}

1. Nichol A, Bailey M, Egi M, Pettila V, French C, Hart GK, Stachowski E, Reade MC, Cooper DJ, Bellomo R: Dynamic lactate indices as predictors of outcome in critically ill patients. Crit Care 2011, 15:R242.

2. Scheele KW: Opuscula Chemica et Physica. Leipzig; 1788.

3. Kompanje EJ, Jansen TC, van der Hoven B, Bakker J: The first demonstration of lactic acid in human blood in shock by Johann Joseph Scherer (1814-1869) in January 1843. Intensive Care Med 2007, 33:1967-1971.

4. Broder G, Weil MH: Excess lactate: an index of reversibility of shock in human patients. Science 1964, 143:1457-1459.

5. Vincent JL, Dufaye P, Berre J, Leeman M, Degaute JP, Kahn RJ: Serial lactate determinations during circulatory shock. Crit Care Med 1983, 11:449-451.

6. Abramson D, Scalea TM, Hitchcock R, Trooskin SZ, Henry SM, Greenspan J: Lactate clearance and survival following injury. J Trauma 1993, 35:584-588; discussion 588-589.

7. Bakker J, Gris P, Coffernils M, Kahn RJ, Vincent JL: Serial blood lactate levels can predict the development of multiple organ failure following septic shock. Am J Surg 1996, 171:221-226.

8. Suistomma M, Ruokonen E, Kari A, Takala J: Time-pattern of lactate and lactate to pyruvate ratio in the first 24 hours of intensive care emergency admissions. Shock 2000, 14:8-12.

9. Nguyen HB, Rivers EP, Knoblich BP, Jacobsen G, Muzzin A, Ressler JA, Tomlanovich MC: Early lactate clearance is associated with improved outcome in severe sepsis and septic shock. Crit Care Med 2004, 32:1637-1642.

10. Arnold RC, Shapiro NI, Jones AE, Schorr C, Pope J, Casner E, Parrillo JE, Dellinger RP, Trzeciak S: Multicenter study of early lactate clearance as a determinant of survival in patients with presumed sepsis. Shock 2009, 32:35-39.

11. Claridge JA, Crabtree TD, Pelletier SJ, Butler K, Sawyer RG, Young JS: Persistent occult hypoperfusion is associated with a significant increase in infection rate and mortality in major trauma patients. J Trauma 2000, 48:8-14. discussion 14-15.

12. Rossi AF, Khan DM, Hannan R, Bolivar J, Zaidenweber M, Burke R: Goaldirected medical therapy and point-of-care testing improve outcomes after congenital heart surgery. Intensive Care Med 2005, 31:98-104.

13. Jones AE, Shapiro NI, Trzeciak S, Arnold RC, Claremont HA, Kline JA: Lactate clearance vs central venous oxygen saturation as goals of early sepsis therapy: a randomized clinical trial. JAMA 2010, 303:739-746.

14. Jansen TC, van Bommel J, Schoonderbeek FJ, Sleeswijk Visser SJ, van der Klooster JM, Lima AP, Willemsen SP, Bakker J: Early lactate-guided therapy in intensive care unit patients: a multicenter, open-label, randomized controlled trial. Am J Respir Crit Care Med 2010, 182:752-761

15. Finney SJ, Zekveld C, Elia A, Evans TW: Glucose control and mortality in critically ill patients. JAMA 2003, 290:2041-2047.

doi:10.1186/cc10531

Cite this article as: Nguyen HB: Lactate in the critically ill patients: an outcome marker with the times. Critical Care 2011, 15:1016. 